\title{
Compressed fuzzy logic based multi-criteria AODV routing in VANET environment
}

\author{
Taqwa Oday Fahad ${ }^{1}$, Abduladhem A. Ali ${ }^{2}$ \\ ${ }^{1}$ Department of Biomedical Engineering, University of Technology, Iraq \\ ${ }^{2}$ Department of Computer Engineering, University of Basra, Iraq
}

\begin{tabular}{l}
\hline Article Info \\
\hline Article history: \\
Received Jan 28, 2018 \\
Revised Aug 31, 2018 \\
Accepted Sep 13, 2018 \\
\hline
\end{tabular}

Keywords:

AODV routing protocol compressed fuzzy logic Real world traffic simulation VANET

\begin{abstract}
Vehicular ad hoc networks (VANETs) are the core of intelligent transportation systems (ITS) to obtain safety, better transportation services, and improved traffic management. Providing more reliable and efficient on demand routing protocol is one of the main challenges in these networks research scope. This paper argues a compressed fuzzy logic based method to enhance Ad hoc on demand distance vector (AODV) routing decision by jointly considering number of relays, distance factor, direction angle, and vehicles speed variance. The proposed scheme is simulated in both freeway and urban scenarios with different number of vehicles using real time interaction between both OMNet++ and SUMO simulators. Simulation results show that the proposed approach can get better performance in terms of packet delivery ratio, throughput, mean delay, and number of sent control packets.
\end{abstract}

Copyright (C) 2019 Institute of Advanced Engineering and Science. All rights reserved.

\section{Corresponding Author:}

Taqwa Oday Fahad,

Department of Biomedical Engineering,

University of Technology, Iraq.

Email: taqwa.odey@gmail.com

\section{INTRODUCTION}

Vehicular Ad hoc Network (VANET) [1-4] is a challenging subclass of Mobile Ad hoc Network (MANET), where vehicles are equipped with wireless transceiver and GPS receiver, sensors to measure required parameters, and central processing unit which run various protocols to form a wireless network of vehicles that are distributed and self-organized. Unlike MANET, VANET is restricted by road direction, traffic, and traffic regulation; furthermore, vehicles move at high speeds causing higher dynamic topology, and frequent disconnected network. These special characteristics make routing in VANET is one of the major issues in research topic, some of these works are:

M. Abdelgader et. al. [5] evaluate the performance of DSR, AODV, and DSDV routing protocols in city scenario. C. Wu et. al. [6] use fuzzy logic to evaluate each direct link in AODV routing considering multiple factors of bandwidth, mobility, and signal strength. C. Lin et. al. [7] propose fuzzy model based routing to decide network connectivity of road segment considering vehicle density and average velocity. R. Kadivar et. al. [8] introduce a fuzzy logic based DSR routing protocol to select the most stable route considering distance and degree of variation in the speed of the driver. S. Chang et. al. [9] suggest distance based routing protocol in urban environment that take into account packet collision avoidance in the intersection and route decision depending on adaptive waiting time.However, it is important to observe that the proposed schemes presented in the related works are mostly focused on only two or three factors in their studies. In this work, an improved AODV routing protocol [10-13] is proposed considering a new combination of attractive significant factors regard number of relay nodes, distance in related to transmission range, angle of movement, and speed variance as inputs to a compressed fuzzy system to solve impression and conflict between these proposed metrics. 
In spite of the great efficient of using the conventional fuzzy system in numerous applications [14-19] that deal with impression and uncertainty, as the number of fuzzy inputs increased, the number of fuzzy rules and fuzzy operations are also increased in an exponential manner [20, 21].

Many efforts have been devoted to deal with above-mentioned fuzzy complexity problem. Some of the proposed methods based on removing or merging of fuzzy rules which might cause information loss or aggregation, and others interested on decomposing the fuzzy system into subsystems and multilayer hierarchical structure which might suffer from poor interaction of actually inputs [22].

A. Gegov et. al. introduced a compressed fuzzy rule based system [23, 24] that remove all redundant on line fuzzy operations without affecting the fuzzy output. Although this proposed compressed fuzzy methods has proven a significant reduction in fuzzy system operations as compared with conventional and hierarchical fuzzy systems, it can be notice that only a few researches have been used this method, and the present work is the first one that apply this method in computer network field, and VANET environment to reduce processing time and complexity of adding a fuzzy system.

\section{RESEARCH METHODOLOGY}

The AODV routing protocol is modified in such a manner that it can select the appropriate route for data packet using compressed fuzzy logic that join multiple criteria:

a) Number of relay vehicles in the path.

b) Inter vehicle distance in related to vehicle transmission range.

c) Movement speed variance between any two successive vehicles in the path.

d) Angle of direction of any vehicle in the path with respect to destination direction.

Apart from these applied fuzzy system inputs, the key idea behind the method of compressed fuzzy system is represented by arranging the fuzzy rules into groups; each group contains the rules with identical linguistic variable for the output, thereafter determine the dominant rule that have the maximal firing strength in each group and remove all other rules.

As a result, the number of rules will be equal to the number of linguistic variables of the output, so only six rules from eighty one rules remains after fuzzification in our designed system. This leads to a substantial reduction of fuzzy inference online computations, which guarantee a betterment by about ten times over the conventional system and by about three and a half times over the hierarchical system [23, 24].

\section{SIMULATION SCENARIO}

Bidirectional coupling of traffic simulator: Simulation of Urban Mobility (SUMO) and network simulator: Objective Modular Network Testbed in $\mathrm{C}++(\mathrm{OMNeT}++)$ at runtime were used for online reconfiguration and rerouting of cars in reaction to network simulator.

The required files for building three different maps to be used in our simulation were generated using the provided commands in SUMO, where openstreetmap website was used to download the second and third map for more realistic simulation:

a) Simple Map:

b) Consist of six vertical streets each of 2 lanes, $2 \mathrm{~km}$ in length; intersect with three horizontal streets each of 2 lanes, $2.5 \mathrm{~km}$.

c) City Scenario: $3 \mathrm{Km}$ by $3 \mathrm{Km}$ from Basra City Map.

d) Highway Scenario: $3 \mathrm{Km}$ by $3 \mathrm{~km}$ from I $95 \mathrm{Map}$.

Network simulation parameters were specified using OMNeT++, where 100, 200, and 300 vehicles were tested for each map with TraCI mobility model, IEEE $802.11 \mathrm{p}$ was used as a medium access control protocol, UDP data traffic with packet size of 512B was used, and each simulation was executed for 1000 seconds of simulation time.

\section{SIMULATION RESULTS}

The above proposed scheme (Comp-FAODV Routing) has been implemented and compared with another three protocols: (i) conventional AODV routing protocol; (ii) Fuzzy Logic Routing Based on forwarding optimization (FLRBF): a new scheme [25] that depends mainly on fuzzifying two factors regard distance and time delay that is calculated through the information of location, transmission range, and velocity; and finally with another implemented protocol (iii) (Fuzzy-AODV Routing) whereby only the first three above-mentioned criteria in research methodology section are taken as inputs to a traditional fuzzy system.

Int J Elec \& Comp Eng, Vol. 9, No. 1, February 2019 : 397 - 401 
The performance evaluation of all the implemented protocols are carried out in terms of packet delivery ratio as shown in Figure 1, throughput as shown in Figure 2, mean delay as shown in Figure 3, and number of sent control packets as shown in Figure 4, each tested for different number of vehicles in simple map as shown in Figures (x-a), city asshown in Figures (x-b), and freeway as shown in Figures (x-c) scenarios.

The obtained results show that the proposed method (Comp-FAODV Routing) gives the best performance results, and the method (Fuzzy-AODV Routing) outperforms the conventional AODV and FLRBF routing methods.

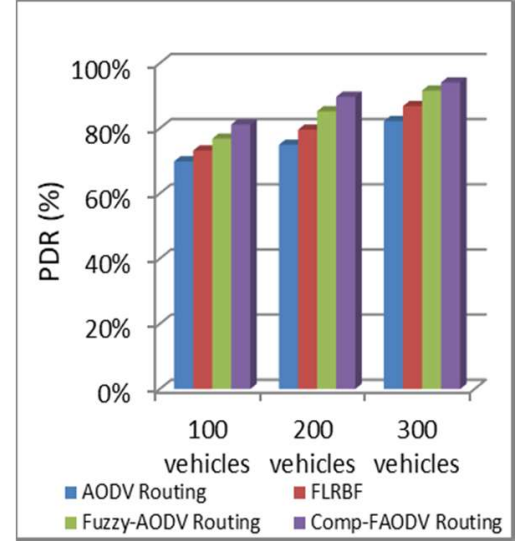

(a) Simple Map

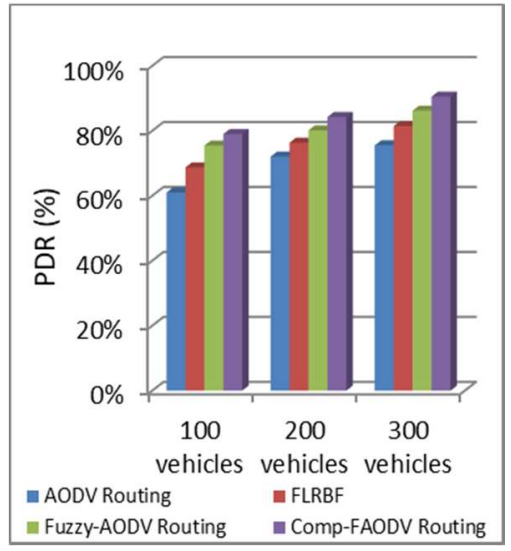

(b) City Scenario

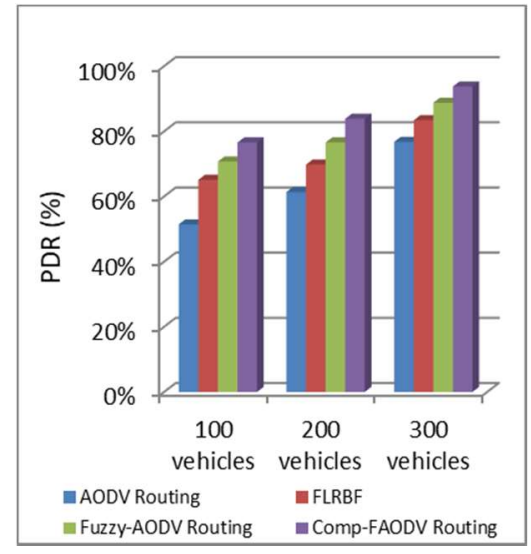

(c) Highway Scenario

Figure 1. Packet delivery ratio (\%) vs. no. of vehicles

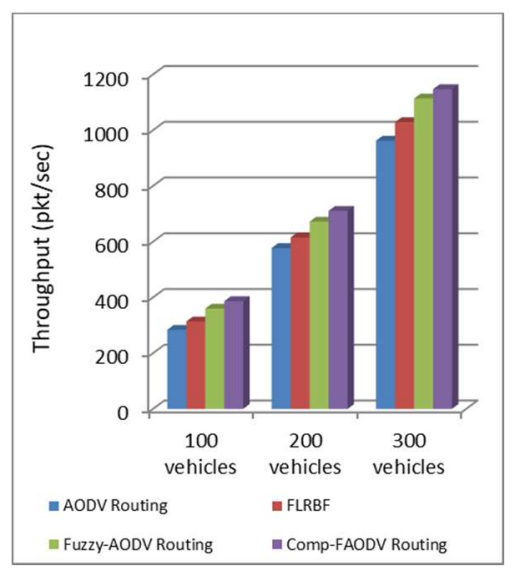

(a) Simple Map

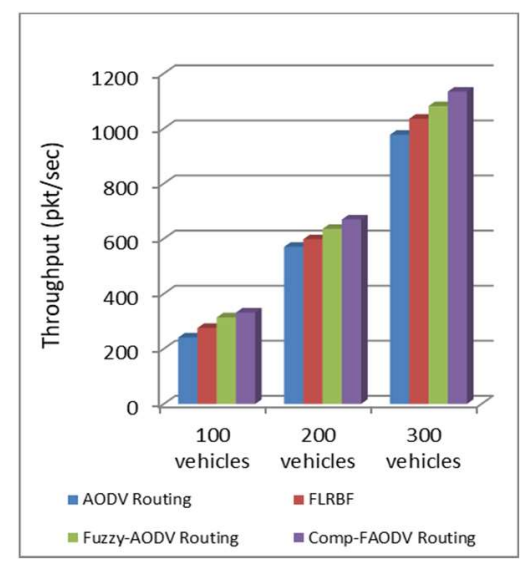

(b) City Scenario

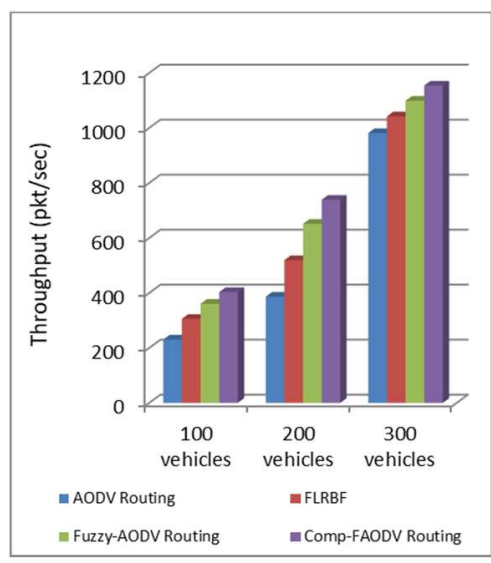

(c) Highway

Figure 2. Throughput (pkt/sec) vs. no. of vehicles 


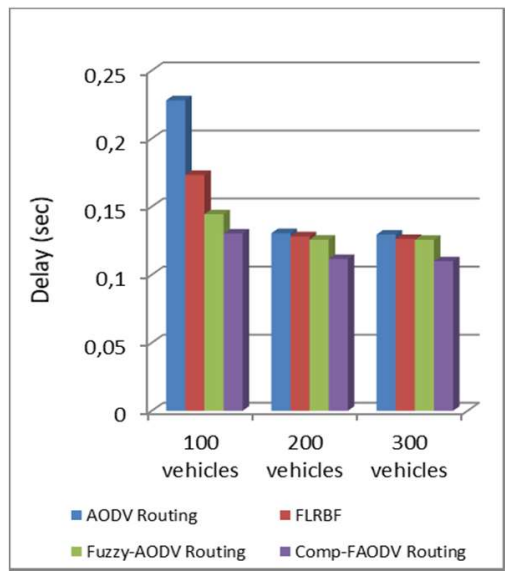

(a) Simple Map

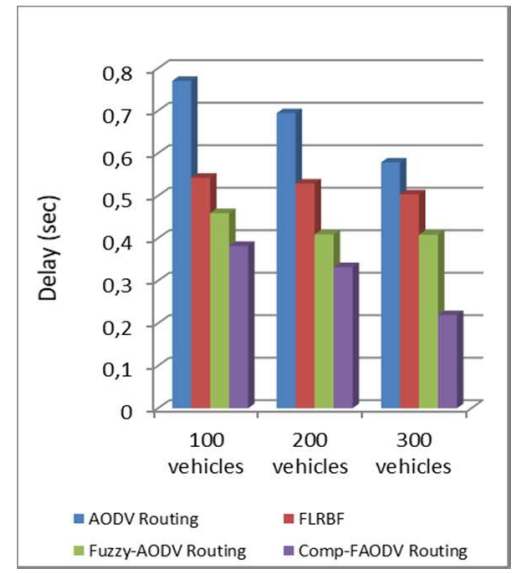

(b) City Scenario

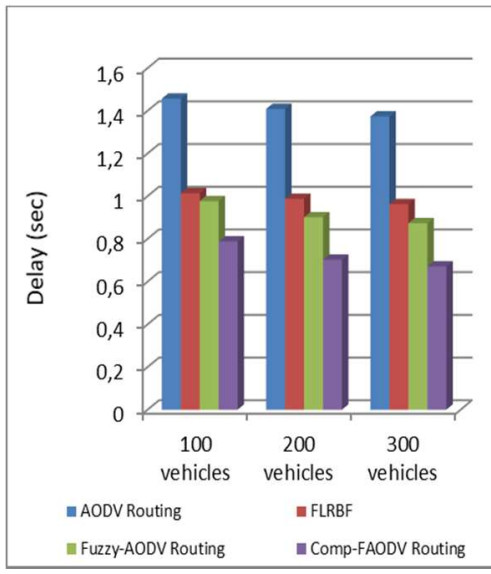

(c) Highway Scenario

Figure 3. Mean delay (Sec) vs. no. of vehicles

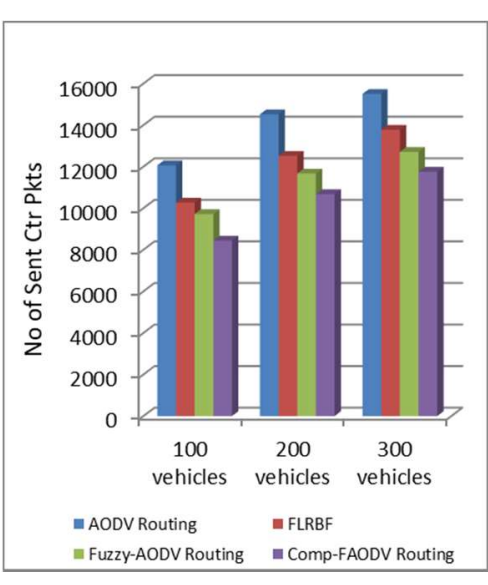

a) Simple Map

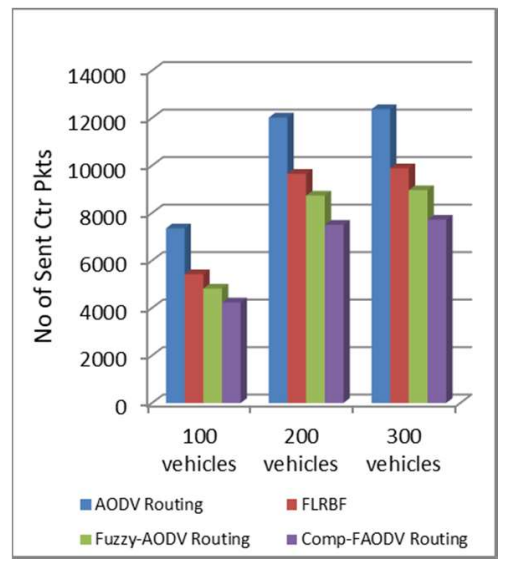

(b) City Scenario

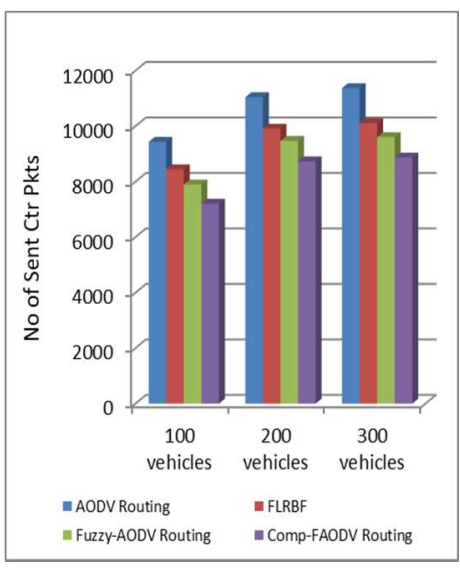

(c) Highway Scenario

Figure 4. No of sent control packets vs. no of vehicles

\section{CONCLUSION AND FUTURE WORKS}

In this paper, VANET simulation and required tools to simulate two urban and one freeway scenarios are built, two of them are real maps of Basra city and i95 highway. Furthermore, two fuzzy multi criteria based methods for AODV routing decision are proposed and carried out on these maps; the first one investigates three effective factors in VANET environment regards number of relay nodes, distance with respect to transmission range, and speed of movement of vehicles. The second method extends the first proposed system to adopt an additional factor of vehicle's direction; moreover, the proposed fuzzy system is compressed to reduce computations complexity of considering many factors. Simulation results demonstrated the effectiveness and efficiency of the proposed schemes. Future works may consider other possible intelligent techniques.

\section{REFERENCES}

[1] D. Benhaddou, A. Al-Fuqaha, "Wireless Sensor and Mobile Ad-Hoc Networks: Vehicular and Space Applications", Springer, 2015.

[2] D. Rawat, C. Bajracharya "Vehicular Cyber Physical Systems", Springer, 2017.

[3] A. Laouiti, A. Qayyum, M. Saad, "Vehicular Ad-Hoc Networks for Smart Cities", Springer, 2017.

[4] M. Dixit, R. Kumar, A. Kumar, "VANET: Architectures, Research Issues, Routing Protocols, and Its Applications", International Conference on Computing, Communication and Automation (ICCCA), IEEE, pp. 555$561,2016$. 
[5] M. Abdelgadir, R. Saeed, A. Babiker, "Mobility Routing Model for Vehicular Ad-hoc Networks (VANETs), Smart City Scenarios", Vehicular Communications Journal, Elsevier, pp. 154-161, 2017.

[6] C. Wu, S. Ohzahata, T. Kato, "Routing in VANETs: A fuzzy Constraint Q-Learning Approach", Global Communications Conference (GLOBECOM) IEEE, pp. 195-200, 2012.

[7] C. Lin, F. Dong, K. Hirota, "Fuzzy Road Situation Model Optimization Routing (FRSMOR) in Vehicular Ad hoc Network (VANET)", The 6th International Conference on Soft Computing and Intelligent Systems (SCIS) and The 13th International Symposium on Advanced Intelligence Systems (ISIS), IEEE, pp. 532-537, 2012.

[8] R. Kadivar, R. Sabbaghi-Nadooshan, A. Dana, "Fuzzy Logic Based Stable Routing in VANET", Elixir International Journal, Ad hoc Network 56, pp. 13413-13416, 2013.

[9] S. Chang and S. Lee, "Distance-Based Stable Routing Decision Scheme in Urban Vehicular Ad Hoc Networks", International Journal of Distributed Sensor Networks, Hindawi Publishing, vol. 11, no. 8, Article ID 245439, 2015.

[10] H. Zhang, J. Guo, "Application of Manet Routing Protocol in Vehicular Ad hoc Network Based on NS3", 7th International Conference of Electronics Information and Emergency Communication (ICEIEC), IEEE, 2017.

[11] B. Marzak , H. Toumi, E. Benlahmar, M. Talea,"Performance Analysis of Routing Protocols in Vehicular Ad Hoc Network. In: Advances in Ubiquitous Networking 2", Springer, vol. 397, pp. 31-42, 2017.

[12] R. Brendha, V. Prakash, "A Survey on Routing Protocols for Vehicular Ad Hoc Networks", 4th International Conference on Advanced Computing and Communication Systems (ICACCS) IEEE, 2017.

[13] R. Desai, B. P. Patil, D. P. Sharma, "Routing Protocols for Mobile Ad Hoc Network: A Survey and Analysis", Indonesian Journal of Electrical Engineering and Computer Science, vol. 7, no. 3, pp. 795-801, 2017.

[14] A. Prayitno, V. Indrawati, I. I. Trusulaw, "Fuzzy Gain Scheduling PID Control for Position of the AR.Drone", International Journal of Electrical and Computer Engineering (IJECE), vol. 8, no. 4, pp. 1939-1946, 2018.

[15] G. M. Reddy, T.G. Manohar, "Fuzzy Logic Controller for Power Balance Theory Based STATCOM for Grid Connected Wind Turbine System", Indonesian Journal of Electrical Engineering and Computer Science, vol. 11, no. 1, pp. 409-412, 2018.

[16] Abduladhem A Ali, Taqwa O. Fahad, "Fuzzy Energy based Routing Protocol for MANET", International Journal of Computer Applications, vol. 46, no. 1, pp. 38-40, 2012.

[17] J. Kacprzyk, E. Szmidt, S. Zadrożny, K. Atanassov, M. Krawczyk, “Advances in Fuzzy Logic and Technology 2017”, Springer, 2018.

[18] S. Santini, A. Pescape, A.Valente, V. Abate, G. Improta, M. Triassi, P. Ricchi, A. Filosa, "Using Fuzzy Logic for Improving Clinical Daily-Care of beta-thalassemia Patients", IEEE International Conference on Fuzzy Systems, FUZZ, 2017.

[19] T. Odey, A. A. Ali, "Fuzzy Controller Based Stable Routes with Lifetime Prediction in MANETs", International Journal of Computer Networks (IJCN), vol. 3, no. 1, pp. 37-42, 2011.

[20] M. Mohammadian, "Modelling, Control and Prediction using Hierarchical Fuzzy Logic Systems: Design and Development”, International Journal of Fuzzy System Applications, vol. 6, no. 3, pp. 105-123, 2017.

[21] P. C. Shill, "Fuzzy Logic Controllers: Optimization Issues on Design and Rule Base Reduction Algorithms", Ph. D. thesis, University of Fukui, Japan, 2013.

[22] A. Gegov, D. Sanders, B. Vatchova, "Aggregation of Inconsistent Rules for Fuzzy Rule Base Simplification", International Journal of Knowledge-based and Intelligent Engineering Systems, vol. 21, no. 3, pp. 135-145, 2017.

[23] A. Gegov, N. Gobalakrishnan, D. Sanders, "Filtration of Non-Monotonic Rules for Fuzzy Rule Base Compression", International Journal of Computational Intelligence Systems, vol. 7, no. 2, pp. 382-400, 2014.

[24] A. Gegov, "Complexity Management sin Fuzzy Systems”, Springer, Berlin, 2007.

[25] Z. Miao, X. Cai, Q. Luo, W. Dong, "A FLRBF Scheme for Optimization of Forwarding Broadcast Packets in Vehicular Ad Hoc Networks", 27th Annual IEEE International Symposium on Personal, Indoor and Mobile Radio Communications-(PIMRC): Mobile and Wireless Networks, IEEE 2016. 